\title{
Fetal Stem Vessel Thrombus with or without Dystrophic Calcification
}

National Cancer Institute

\section{Source}

National Cancer Institute. Fetal Stem Vessel Thrombus with or without Dystrophic

Calcification. NCI Thesaurus. Code C117333.

A focus of thrombus adhered to the wall of a fetal stem vessel. It can be completely or partially obstructive and may lead to downstream villous injury and calcification. 